\title{
Stress and Atopic Dermatitis
}

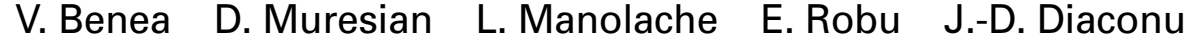 \\ Dermato-venereological Center, 'Scarlat Longhin' Clinic Hospital for Dermatology, Bucharest, Romania
}

\section{Key Words}

Atopic dermatitis · Stress

\begin{abstract}
Summary
Objective: The aim of this study was to evaluate the implication of stress in the development of atopic dermatitis.

Patients and Methods: The study was performed on 240 patients with atopic dermatitis who attended the Allergy Unit of the Dermato-venereological Center Bucharest. The relationship between stress and the evolution of the disease was evaluated. 50 of the patients were also evaluated by a psychologist trying to find a 'personality type' for atopy.
\end{abstract}

Results: Age of patients ranged from less than 2 to 67 years (mean age 17.2). 59.58\% were female. $62.9 \%$ of the patients had mild, 26.7 moderate and 10.4 severe atopic dermatitis. Stress was the main factor that triggered the disease in $5.83 \%$ of cases $(7.92 \%$ for women) and aggra- vated the development in $45.42 \%$ of cases. The psychological examination showed emotional instability in 37 cases $(74 \%)$, anxious depression in 33 cases $(66 \%)$, impossibility to pass over frustrating situations in 23 cases $(46 \%)$, difficulties in adjustment in 17 cases $(34 \%)$, psychasthenical personality (existential insecurity) in 26 cases $(52 \%)$, and disharmonic personality in 19 cases $(38 \%)$. In addition, for $34 \%$ of patients the long duration of the disease induced perturbations of personality. The IQ evaluation showed a normal intelligence for $30 \%$ of patients, above-average in 52, below-average intelligence in 14, and mental defectiveness in $4 \%$. The classical atopic personality was identified in $40 \%$ of the patients psychologically examined.

Conclusions: This study shows the importance of stress as a factor for aggravation and development of atopic dermatitis. This fact is important in the management of patients with atopic dermatitis.

\section{Introduction}

Atopy is a genetically determined disorder characterized by an increased liability to form Ig E antibodies (reagins) and an increased susceptibility to certain diseases, especially extrinsic asthma, allergic rhinitis, allergic conjunctivitis, and certain types of food allergy; the main clinical type of dermatitis usually associated with atopy is atopic dermatitis. Many epidemiological studies indicate that the incidence of atopic dermatitis has doubled or tripled over past decades [25]; this increase is more evident in developed countries, where atopic dermatitis affects $10-20 \%$ of population.

The major causes of atopic dermatitis remain unknown [2, $4-6,15]$. The clinical manifestations seem to depend on a com- plex interplay between genetical, constitutional, and environmental factors. Any attempt to explain pathogenesis must take into account the following important features of the disease: marked pruritus, varied and continually changing morphology of skin lesions, increased serum Ig E levels in most patients, increased susceptibility to cutaneous viral and bacterial infections, and fluctuating abnormalities in cell-mediated immunity and beta-adrenergic responsiveness. Stress seems to be an important trigger for atopic dermatitis also being in volved in the aggravation and maintenance of the disease. The aim of this study was to assess the involvement of stress in the development of atopic dermatitis.

\begin{tabular}{ll}
\hline KARGER & @ 2001 S. Karger GmbH, Freiburg \\
Fax +4976145207 14 & Accessible online at: \\
$\begin{array}{l}\text { E-mail Information@Karger.de } \\
\text { www.karger.com }\end{array}$ & www.karger.com/journals/dps
\end{tabular}

Dr. Liana Manolache

str Cetatea Histria nr 12, sector 6

Bucharest, Romania

Tel. +4014113616

E-mail liana@fx.ro 


\section{Patients and Methods}

The study was performed among 240 patients with atopic dermatitis who were referred for allergologic assessment and follow-up to the Allergy Unit of the Dermato-venereological Center Bucharest.

The clinical diagnosis of atopic dermatitis was made according to the definition of Hanifin and Rajka [11]. The severity was assessed by use of SCORAD [7]. Patients were grouped by age: younger than 2 years (22 cases; $9.2 \%$ ), 2-5 years (35 cases; $14.6 \%$ ), 6-10 years (54 cases; $22.5 \%$ ), $11-20$ years ( 60 cases; $25 \%$ ) and over 20 years ( 69 cases; $28.8 \%$ ).

The relationship between stress and development (triggering, aggravation, maintenance) of atopic dermatitis was systematically evaluated. Stress was evaluated using the 'Life Events Scale' [13], considering a score of more 200/year a risk for a psychosomatic disease. A psychologist also evaluated 50 of the patients from all age groups enrolled in the study trying to search for an 'atopic personality type', no control group was evaluated.

\section{Results}

The age of patients ranged from less than 2 to 67 (mean age $17.2)$ years. 151 patients $(62.9 \%)$ had mild, 64 (26.7\%) moderate and $25(10.4 \%)$ severe atopic dermatitis.

Stress was precipitating the development of atopic dermatitis lesions in 14 cases $(5.83 \%)$. Other trigger-factors were infections in 41 cases $(17.08 \%)$, unspecific irritants in 17 cases $(7.08 \%)$, prurigo in 16 cases $(6.66 \%)$, the exposure to aeroallergens in 7 cases $(2.92 \%)$, food allergens in 6 cases $(2.50 \%)$, local trauma in 4 cases $(1.66 \%)$, vaccinations in 3 cases $(1.25 \%)$ and sun burns in 3 cases $(1.25 \%)$. For the rest of the patients it was impossible to find a single and very clear trigger. Usually it was a combination of trigger factors, mostly infection, food allergens, and stressful events. However, the combination was not included in the evaluation. Stress was identified as triggering factor in patients older than 6 years. It was more important in developing the disease for women (11 of 142 female patients; $7.72 \%$ ) than for men (3 of 98 male patients; $3.07 \%$ ) and in the groups of patients older than 20 years. For children between 6 and 10 years the stressful event was the beginning of school.

Of the patients enrolled in the study 109 (45.42\%) have noticed the exacerbation of skin lesions during or after a stressful life event. Other factors involved in the exacerbation of the symptoms were unspecific irritants (wool in 132 cases, 55\%; excessive sweat in 99 cases, $41.25 \%$; soaps and/or detergents in 97 cases, $40.42 \%$ ), the exposure to aeroallergens in 53 cases, $(22.08 \%)$, food allergens in 17 cases, $(7.08 \%)$ and hormonal events (especially the menses) in 6 cases $(2.5 \%)$.

Neurotic disorders (anxious-depressive neurotic syndrome) were diagnosed by the psychologist in 8 of the patients $(3.33 \%)$. Among the 50 patients evaluated by the psychologist, 37 cases of emotional instability (74\%), 33 cases of anxious-depressive disorder (66\%), 23 cases of inability to overcome frustrating situations $(46 \%)$ and 17 cases of difficulties in adjustment $(34 \%)$ were detected. These disorders were mostly (47 cases, $82 \%$ ) a reaction to family, professional, or school problems. In 28 cases $(56 \%)$ the problems were familial: disorganized families, lack of parental affection (especially the mother's). Job problems were detected in 9 cases $(18 \%)$ and school problems in 4 cases $(8 \%)$.

On the other hand, for 17 patients (34\%) who underwent psychological tests, the long duration of the disease induced the development of personality disorders (disharmonic personality in 9 cases, psychasthenic personality in 5 cases, aggressiveness in 3 cases) and also perturbations joining the school or society.

Evaluation of the IQ showed normal intelligence in $30 \%$ of patients, above-average in 52, below-average in 14, and mental defectiveness in $4 \%$. The classical atopic personality (outwardly calm but seething with suppressed anxieties, frustration, insecurity, aggression, and egotism; above-average intelligence) was identified in $40 \%$ of the patients psychologically examined.

\section{Discussion}

Dermatological disorders are influenced by three essential components: biological, psychological and socio-environmental factors. Usually, theoretical models are centered on a single aspect. Dermato-psychology creates a link between dermatology and psychology; it tries to establish a relation between a conflicting emotional situation, personality structure and dermatological disorder $[10,12,18,22,23]$. The role of genetic predisposition of atopic dermatitis is well known, but other factors are also involved (immunological and non-immunological). Very important non-immunological factors are the psychosocial ones. Atopic dermatitis, as well as other dermatological diseases (mostly psoriasis, alopecia areata, acne vulgaris, etc.) is considered a psychosomatic disease in which psychological factors have an impact on the development of disease and can increase the symptoms. Stressful events, as well as the personality type are co-factors, and active episodes of the disease are often related to a high level of stress $[9,14$, 24]. On the other hand, atopic dermatitis as a disfiguring disease is a stressor itself with an influence on the psychosocial state of the patient and on the maintenance of the lesions. There is evidence that the central and peripheral nervous system in association with the immune system plays a role in modulating the expression of various dermatological diseases. Close connections between the epithelium, immune cells, and the nervous system were demonstrated, so a new concept of a neuro-immuno-cutaneous system has been proposed $[1,3,5$, 16, 17, 19-21]. Links between free nervous terminations and resident cells (keratinocytes, Langerhans cells, mast cells, etc.) of the skin were pointed out [3, 5, 8,16,19-21]. These links are realized through the neuropeptides that are synthesized in the pericarion of the neurons and that transfer the nervous impulse from epithelium to central nervous system [16]. Among the neuropeptides released in the skin are substance P (SP) 
and neurokinin-A (NKA). Many of the resident cells have receptors for neuropeptides and/or can synthesize neuropeptides. Nociceptive C-fibers have receptors for histamine, and neuropeptides (many of them with proinflammatory effects) were identified in the epithelium. Some disorders of the metabolism of neuropeptides are associated with an increased level of proinflammatory neuropeptides (SP plays an important role) and a decreased level of anti-inflammatory neuropeptides in the skin. SP can provoke erythema, pruritus (through histamine released from mast cells), and edema (through direct action on endothelial cells and exteriorization of ELAM-1 on the endothelial cells). SP and NKA have proinflammatory activity as they induce the synthesis of IL-1, IL-6, TNF- $\alpha$.

Stress, as it may occur from anxiety, depression, marital or financial problems, has been identified as a triggering factor in the appearance or exacerbation of atopic dermatitis: the central nervous system can initiate and/or aggravate the atopic inflammation through release of proinflammatory neuropeptides $[16,18]$. On the other hand, the neuropeptides released in the skin during the atopic inflammation have an influence on the central nervous system, disturbing the recognition and perception functions as well as the behavior of the atopic patients [16].

This study shows that stress alone is not the most important trigger factor (only $5.83 \%$ of patients), but it is a very important factor in maintaining the dermatitis $(45.42 \%)$ and the disease itself could be a stressor for the patient, opening a vicious circle (17 of 50 interviewed patients; $34 \%$ ).

Although an 'atopic personality type' is described in the literature, no specific personality traits or interpersonal adjust- ment problems have been conclusively identified in patients with atopic dermatitis [6]. In the 50 patients evaluated to detect an 'atopic personality', anxious-depressive symptoms, or emotional instability seem to predominate. However, comparison with a control group would be necessary to obtain meaningful data.

As part of the total care of the patients with atopic dermatitis, physicians are urged to augment the classic treatment regimens with psychotropic drugs (especially psychotropic drugs with an antihistaminic effect) and with stress-reduction strategies [22]. We have used hidroxyzine (for both antihistaminic and anxiolytic effect) and most of all doxepin (as the most powerful antihistaminic drug, antidepressant and also anxiolytic) with very good results on the pruritus and also on anxious symptoms associated. Stress management is also important. Therefore, in our clinic supportive counseling is offered. Other possibilities for stress management would be biofeedback or relaxation techniques.

\section{Conclusions}

Stress is involved as a possible precipitating and aggravating factor in atopic dermatitis, and the disease itself can be a psychosocial stress, which maintains the disease. This fact is important in the management of patients with atopic dermatitis: psychotropic, antipsychotic, and anxiolytic drugs, antidepressants, and psychotherapy are recommended as additional treatment strategies. Very important in the treatment of atopic dermatitis are also the psychotropic drugs with an antihistaminic effect (doxepine, hydroxyzine, amitriptyline).

\section{References}

1 Ader R (ed): Psychoneuroimmunology. New York, Academic Press, 1981.

2 Ballmer-Weber BK: Atopische Dermatitis. Praxis 1998:87:1293-1299.

3 Bos JD, Kapsenberg ML: The skin immune system: Progress in cutaneous biology. Immunol Today 1993;14:75-80.

4 Bos JD, Sillevis Smitt JH: Atopic dermatitis. J Eur Acad Dermatol Venereol 1996;7:101-114.

5 Braun-Falco O, Plewig G, Wolff HH, Winkelman RK: Dermatology. New York, Springer, 1991.

6 Champion RH, Parish WE: Atopic dermatitis; in Champion RH, Burton JL, Ebling FGJ (eds): Rook Textbook of Dermatology. Oxford, Blackwell, 1992, pp 589-610.

7 European Task Force on Atopic Dermatitis: Severity scoring of atopic dermatitis: The SCORAD index. Dermatology 1993;186:23-31.

8 Gaudillere A, Misery L, Souchier C, Claudy A: Intimate associations between PGP 9.5-positive nerve fibers and Langerhans cells. Br J Dermatol 1996; 135:343-344.
9 Gauthier Y: Stress et peau: Approche experimentale. Nouv Dermatol 1997;16:25-26.

10 Gupta MA, Gupta AK: Psychodermatology: An update. J Am Acad Dermatol 1996;34:1030-1046.

11 Haynal A, Pasini W: Medecine psychosomatique. Masson, 1984

12 Hanifin J, Rajka G: Diagnostic features of atopic dermatitis. Acta Derm Venereol (Stockh) 1980;92 (suppl):44-47.

13 Holmes TH, Rahe RH: The Social Readjustment Rating Scale. J Psychosom Res 1967;11:213-218.

14 Koblenzer CS: Psychologic aspects of skin disease; in Fitzpatrick TB, Eisen AZ, Wolf K (eds): Dermatology in General Medicine. New York, Mc GrawHill, 1993, pp 14-26.

15 Laihinen A: Assessment of psychiatric and psychosocial factors disposing to chronic outcome of dermatoses. Acta Derm Venereol 1991;156:46-48.

16 Leung DYM, Rhodes AR, Geha RS, Schneider L, Ring J: Atopic dermatitis (Atopic eczema); in Fitzpatrick TB, Eisen AZ, Wolf K, Freedberg IM, Austen KF (eds): Dermatology in General Medicine, ed 4. New York, Mc Graw-Hill, 1993, pp 1543-1563.
17 Lotti T, Hautmann G, Panconesi E: Neuropeptides in skin. J Am Acad Dermatol 1995:33:482-496.

18 Misery L: Le systeme neuro-immuno-cutane. Nouv Dermatol 1997;16:21.

19 Misery L: Pourquoi des problèmes psychologiques aggravent-ils certaines dermatoses? Ann Dermatol Venereol 1997;124:804-805.

20 O'Sullivan RL, Lipper G, Lerner EA: The neuroimuno-cutaneous-endocrine network. Relationship of mind and skin. Arch Dermatol 1998;134:14311435.

21 Ortonne JP: Place de la cellule Merkel dans le système neuro-cutane. Nouv Dermatol 1997;16:18-19.

22 Reznik M: Structure et fonctions du systeme nerveux cutane. Nouv Dermatol 1997;16:14-15.

23 Tordeurs D, Poot F, Janne P, Reynaert CH, Salamon V: Approche psychologique de différentes dermatoses: événements de vie et propension à se plaindre. Ann Dermatol Venereol 2001;128:21-24.

24 Van Moffaert M: Psychodermatology: An overview. Psychother Psychosom 1992;58:125-136.

25 Walton RG: Stress factors in dermatology. Stress Medicine 1985;1:55-60. 